\title{
Kinesio Taping Reduces Cold-Induced Pain in Young Healthy Individuals Independent of the Applied Tension on the Tape
}

Adriano Meireles Filho1, Raniel da Silva Machado1, Tácia Suélen Pereira Cardoso1, Mariana de Souza Costa ${ }^{2}$, Ramon Handerson Gomes Teles ${ }^{1}$, Yago Medeiros Dutra ${ }^{1}$, Francisca Francisete de Sousa Nunes Queiroz ${ }^{1}$, Marcelo de Carvalho Filgueiras ${ }^{2}$

\section{Abstract}

Introduction: Kinesio Taping (KT) is a relatively new method, which has been gaining importance over the past 10 years because of the significant exposure in international sporting events, such as the Olympic games. Although it is widely used by health professionals during treatment, there are few studies that provide information to justify the use of this technique and the ways in which it is applied for the treatment or prevention of any musculoskeletal affliction that causes pain.

Objective: Evaluate the effect of Kinesio Taping on cold-induced pain in young healthy individuals.

Methodology: 85 subjects aged 18 to 38 were selected, divided into a control group (CG: 41) and experimental group (EG: 44). The protocol for induction of pain by cold was done with cold water $\left(0^{\circ} \mathrm{C}-2^{\circ} \mathrm{C}\right)$, with immersion of the non-dominant hand. The variables analyzed were the pain threshold (PT), total time of immersion (TTI) and the pain intensity according to the visual analogue scale (VAS). Kinesio Taping was then applied in an "I" shape, starting from the distal third of the forearm until the end of the third metacarpal bone; in the CG, KT was applied without putting tension on the tape; in the EG, KT was tensioned at $25 \%$ for the application. The volunteers were instructed to keep the KT applied for 24 hours. After this period, the subjects returned to the place of evaluation, where the KT was removed and the pain induction by cold protocol was once again performed.
1 Laboratory of Muscle Morphology and Physiology (LAMFIM) - Universidade Federal do Piauí (UFPI), Campus Ministro Reis Velloso, Parnaíba, Piauí, Brazil.

2 Laboratory of Muscle Morphology and Physiology (LAMFIM) - Biomedical Sciences Graduate's Program Universidade Federal do Piauí (UFPI), Campus Ministro Reis Velloso, Parnaíba, Piauí, Brazil.

Contact information:

Marcelo Carvalho Filgueiras.

Address: Av. São Sebastião, 2819, bairro Santo Expedito. Parnaíba, Pl, Brazil. Tel: (85) 99650685.

¡ professormarcelo@ufpi.edu.br 
Results: In the CG, 17 individuals were male and 24 female, with a mean age of $20.07 \pm 3.11$. In the EG, 21 individuals were male and 23 female, with a mean age of $20.06 \pm 1.88$. There was a significant increase in the variables PT and TTI, in addition to a decrease in the pain intensity according to VAS for both the CG and the EG, without a significant difference between the groups.

Conclusion: KT was able to reduce pain perception induced by the cold, but there was no difference between the experimental and control groups.

\section{Keywords}

Physical Therapy;

Kinesio Taping; Pain.

\section{Introduction}

The main creator and developer of Kinesio Taping (KT), or functional elastic bandaging, was the Japanese chiropractor Kenzo Kase in 1973 [1]. The technique seeks to modify the mechanics of segments, normalizing muscular function by correcting posture, facilitating lymphatic and vascular flow, providing a cutaneous stimulus that facilitates or limits movement, assisting in the reduction of edemas and reducing pain by neural pathways. Although there is little evidence about its effects and mechanisms of action, it is widely used to treat several afflictions in various segments of health care, especially in sports medicine [2-6].

KT can have a distension of $130-140 \%$ and doesn't limit range of motion since it has similar mechanical properties as skin [7, 8]. it's been used in the field of sports, in particular, to protect joints and reduce edema and pain after acute lesions [9]. According to the application technique, the tension applied on the tape and the shape of the strips vary as a function of the purpose of the treatment, with its main effects being the normalization of muscular function, the increase of lymphatic and vascular flow and assisting in the correction of any bad joint alignments and the reduction of pain. The degree of tension of the tape should therefore be linked directly to its effects, being a basic foundation of the technique [10-12].

According to the treatment objective, the shape of the strips and the tension that must be applied on the tape by the therapist, varies. The cuts, for example, can have an "Y" or "I" shape, and the tension applied to the tape, graded in percentages, is described as one of the key factors for the success of the application. This tension ranges from: total $(100 \%)$, intense $(75 \%)$, moderate $(50 \%)$, nothing but the removal of the protective paper or light (15$25 \%)$, to very light (0-15\%) and no tension $0 \%$ [1, 11]. To inhibit muscle pain in acute situations, caused by overuse or stretching, the KT is applied from the distal insertion in the direction of the proximal insertion of the affected muscle (15-25\%) [1, 13].

Although it is widely used, there are few studies that provide information to justify the use of this technique in the treatment or prevention of any musculoskeletal affliction that causes pain. There is controversy in the literature about the nature of the effect being potentially associated with the tape tension and the convolutions of the skin it produces [14]. Bearing in mind that the application of $K T$ is currently popular as a therapeutic resource in different fields of physiotherapy practice, it becomes relevant to seek scientific support to sustain its use 
with respect to its analgesic function and its mode of application [1, 15, 16, 17].

Several studies have described the effects of $K T$ in painful situations. Most of them, however, focused on the treatment of pre-existing injuries, such as lower back pain, often associated with other therapeutic resources $[3,4]$. There is a shortage of studies in the literature about pain effects induced experimentally in healthy individuals, as has been done with other therapeutic resources. The objective of this study was therefore to evaluate the relevance of tension in KT application for the perception of pain by cold experimentally induced in young healthy individuals.

\section{Methodology}

This is a descriptive, longitudinal and prospective study carried out at the Federal University of Piauí. A total of 85 healthy subjects, with a mean age of $20.07 \pm 2.5$, of both genders, participated in the study. All participants signed a written informed consent agreeing with the objectives and methods of the study. The exclusion criteria included people under 18 or over 38 years of age, people reporting any orthopedic or neurological problem, circulatory disorder, allergy to $K T$, hypersensitivity to cold or skin lesions in the area that would be subjected to immersion. The inclusion criteria were healthy individuals at the time of application of the test and being an university student.

The volunteers were divided into two groups, 44 people were part of the experimental group (EG), where the KT was applied with a tension of 25$50 \%$, and 41 of the control group (CG), considered as the placebo, in which the KT was applied without tension. The participants were randomly distributed between the groups and were not informed of which group they were participating. To determine the tension of application, a piece of tape of around $10 \mathrm{~cm}$ was stretched to its maximum and then taken back to below half the size achieved, which resulted in a range between 25 and $50 \%$ of tension.
In the first instance, the previously reported protocol for pain induction by cold was followed [18], in which first the non-dominant hand of the volunteer was immersed in a container containing water at $37^{\circ} \mathrm{C}$ for five minutes to normalize the temperature and then transferred to another container with cold water $\left(0^{\circ} \mathrm{C}-2^{\circ} \mathrm{C}\right)$. The temperature of both containers was controlled by a thermometer for liquids and solutions. The volunteer was instructed to focus on the sensation of the submerged limb until the point at which this sensation became painful, at which time the individual should inform the evaluator, using the term "pain", while keeping the hand submerged until he could no longer support it. He was then given 10 minutes of rest before the procedure was repeated. The time between immersion, the moment in which the participant reported pain, and the total time of immersion, was recorded. The volunteer also indicated the intensity of pain through the Visual Analogue Scale (VAS) on a curve from 0 to $10 \mathrm{~cm}$, where 0 means no pain and 10 means the worst pain imaginable.

In the second instance, KT (Kinesio ${ }^{\circledR}$ Tex GoldTM) was applied in an "I" shape, starting from the distal third of the forearm until the end of the third metacarpal bone, in the posterior region, considering the anatomical position. For the participants of the EG, the KT was tensioned at 25\%, while in the CG the KT was applied without any tension. The volunteer was instructed to keep the KT applied for 24 hours, performing all the activities of daily life as usual. After 24 hours, the KT was removed and the protocol of pain induction by was repeated, including the identical method to record the pain times and intensities as in the initial assessment.

The variables analyzed were elapsed time between the beginning of cryostimulation until the moment in which the volunteer reported pain, the so-called pain threshold (PT), the time that the individual maintained the hand submerged in cold water was called the total time of immersion (TTI) and the pain was evaluated through the VAS. The 
data were organized so as to compare the results between the two instances of the study (pre and post application of the KT).

The analyses between the instances were done using Wilcoxon's test. The normality of the groups was analyzed using the Shapiro-Wilk test. The considered level of significance was $p \leq 0,05$. The tabulation of results was done in the Microsoft Office Excel 2010 software, and the data comparison was performed in the GraphPad Prism 5 software. The project was submitted to the Ethics Committee for Research with Human Beings of the Federal University of Piauí and approved under the registration number: 1,055,201.

\section{Results}

Table 1 shows the distribution of the sample by gender and age of the participants. There were no significant differences of these variables among the volunteers, pointing to the homogeneity of the sample.

With respect to the pain threshold, it was possible to observe a significant increase $(p<0.0001)$ in the time of onset of pain perception in both groups, as can be seen in figure 1 .

The total time of submersion supported by the participants in the study was measured and it was observed that the use of the kinesio tape increased this tolerance in both groups, regardless of tape tension, as can be seen in figure 2 .

The painful sensation was assessed with the $\mathrm{Vi}$ sual Analogue Scale (VAS), applied at the end of

Table 1. Characterization of the groups in terms of gender and age. There was no difference between the mean ages of the experimental and control groups (t-Test; $p=0.9672$ ).

\begin{tabular}{|l|c|c|c|} 
& Experimental & Control & P \\
\hline Gender (M/F) & $21 / 23$ & $17 / 24$ & 0.425 \\
\hline $\begin{array}{l}\text { Age (Mean/ } \\
\text { Standard Deviation) }\end{array}$ & $20.06 \pm 1.88$ & $20.07 \pm 3.11$ & 0.9672 \\
\hline Total & 44 & 41 & \\
\hline
\end{tabular}

Figure 1: Pain threshold. Mean time (s) of the onset of pain perception. An increase can be seen in both groups. * Difference between the final and initial measurement of the experimental group and \# Difference between the initial and final measurement of the control group (Wilcoxon; $p<0.001)$.

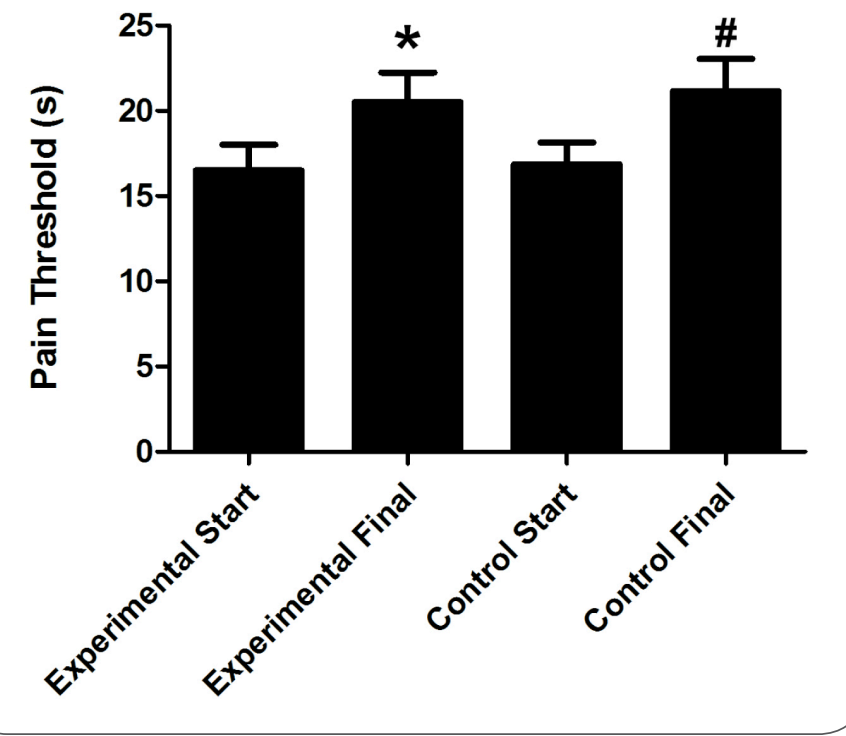

Figure 2: Total Time of Immersion (s). The use of KT provided for a greater tolerance in both groups. * Difference between the final and initial measurement of the experimental group and \# Difference between the initial and final measurement of the control group (Wilcoxon; $p<0.001$ ).

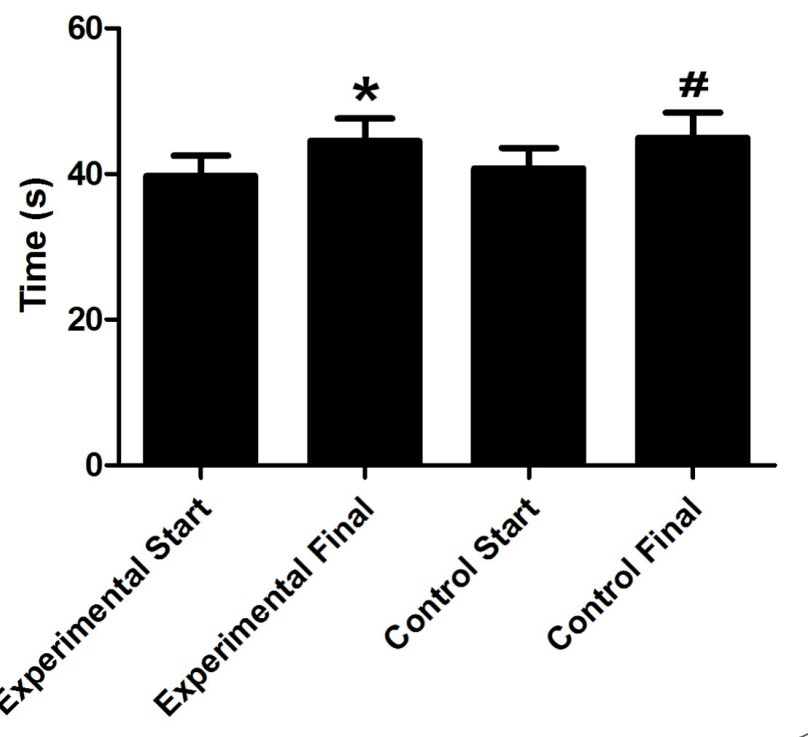


Table 2. Mean VAS values. There was a reduction in pain perception in both groups. (Wilcoxon; $p<0.001^{*}$ ). Variation between the start and final instance of each group (Wilcoxon test; $p<0.6557 \#$ ).

\begin{tabular}{|l|c|c|c|c|}
\multicolumn{1}{c|}{ Group } & $\begin{array}{c}\text { Start } \\
\text { (Mean/deviation) }\end{array}$ & $\begin{array}{c}\text { Final } \\
\text { (Mean/deviation) }\end{array}$ & $\begin{array}{c}\text { Variation } \\
\text { (Mean/deviation) }\end{array}$ \\
\hline Experimental & $6.83 \pm 1.46$ & $6.32 \pm 1.44$ & $<0.0001$ & $-0.49 \pm 1.27$ \\
\hline Control & $7.48 \pm 1.23$ & $6.80 \pm 1.40$ & $<0.0001$ & $0.66 \pm 1.13$ \\
\hline P\# & & & & 0.6557 \\
\hline
\end{tabular}

each experiment. Table 2 shows the means of the results. The application of KT significantly reduced the pain in both groups $(p<0.001)$. However, there was no difference in the comparison of the variation of initial and final values between the groups $(p=0.6557)$, with this variation being $-0.49 \pm 1.27$ points in the experimental group and $0.66 \pm 1.13$ in the control.

\section{Discussion}

The combination of these results reveals that the kinesio tape acts positively, reducing the sensation of pain induced by cold. This effect, however, occurs independent of the tension on the tape, with no statistically significant difference between the experimental and control groups in all evaluated parameters. The similarity of results between the two forms of application, leads us to question the real effectiveness of varying the tension on the tape in the treatment of painful conditions.

Several authors $[2,6,19]$ have carried out studies comparing the effects of the use of $\mathrm{KT}$ in pain situations, such as chronic lumbar pain, acute neck whiplash sprains and medial epicondylitis; all compared the application of KT in two ways, one according to the recommendations of the technique, applying a tape tension of $20-50 \%$ that can cause the skin convolutions, which would be responsible for the technique's effects [1], and another where the tape was applied without tension. The results found corroborate ours and reveal that individuals treated with $\mathrm{KT}$ had a sig- nificant clinical improvement, regardless of the way it is applied, but without difference in results between the groups, supporting the idea that the effect of the tape is not related to the formation of skin convolutions.

The model of cold-induced pain was used because it is a simple method that involves a minimal risk of tissue injury and the pain ceases after the removal of the stimulus. During this test, a painful sensation is generated by temperature receptors, which send stimuli of potential tissue damage through the peripheral ( $C$ and A-delta fibers) and central (spinothalamic and spinoreticular) pathways, resulting in the sensation of pain [20]. This pain induction model has been used by other researchers, particularly to study the effects of transcutaneous electrical stimulation (TENS) $[18,20]$. Its application has proven to be effective for the study of the effects of KT, since its potential mechanism of action would be similar to TENS. Although its mechanism of action is not completely understood, it has been suggested that KT applies a pressure, or stretching to the skin, which possibly stimulates mechanoreceptors that compete with and inhibit nociception through fast conduction myelinated fibers (gate control theory) [21-23].

Other researchers also point to external factors, such as the reduction of lumbar pain after treatment with $\mathrm{KT}$ being associated with a greater body awareness, which could lead the patient to avoid harmful movements [4], or the fact that KT provides a better patellar alignment, thus decreasing pain in patients with patellofemoral pain 
syndrome [23]. One should also take into account the bioneuropsychological pathway, through the release of analgesic neurotransmitters as a function of patient expectations [24].

The participants of both groups were also able to support crioestimulation longer (Figure 2), and the painful experience, evaluated through VAS, was reported as being less intense (Table 3). The reduction of pain with the use of $\mathrm{KT}$ has been reported by other researchers, being singled out as an important factor for the musculoskeletal rehabilitation, providing a positive psychological effect in addition to accelerating the return to routine activities [9, 21].

Our findings show a reduction of pain as assessed with the VAS in both the experimental group and the control group, with no differences occurring between the mean variation in each group, indicating there was no influence of the tape tension on the analgesic effect. While evaluating the intensity of pain in the shoulder through VAS, Thelen and collaborators (2008) observed similar results, with a reduction in pain immediately after application of the $K T$, but this improvement occurred both in the group that received the treatment and the placebo [15]. Corroborating these findings, a study carried out with surgeons using the VAS, revealed that KT was effective in reducing lower back and cervical pain [25].

Recent bibliographical reviews [24, 26, 27], on the other hand, indicate that the clinical application of $\mathrm{KT}$ had no significant result in the reduction of long-term pain or when compared to conventional techniques, such as kinesiotherapy and electrotherapy, for the treatment of musculoskeletal afflictions. These researchers discourage the use of the bandage because they conclude that it has no effect based on the difference between the groups with and without tape tension, or when compared with other resources. One can observe, however, that KT has a positive effect in the treatment of pain, regardless of the format or tension on the tape, with its efficiency being maximized when used as an adjuvant to other, already proven techniques and resources [8].

\section{Conclusion}

Based on this study, we can conclude that KT reduced pain perception induced by the cold, but there was no difference between the experimental and control groups. This effect may therefore be caused by contact of the tape with the skin, regardless of the tension or manner of application. Its therapeutic use should only be recommended when associated with other resources for the treatment of pain. Further studies are recommended, however, to clarify the mechanism of analgesic action in a concrete manner.

\section{Conflicts Of Interest}

All authors declare there were no conflicts of interest.

\section{Contribution Of The Authors}

AMF, RSM, TSPC, YMD and RHGT participated in data acquisition. All authors participated in the review of the manuscript. MCF guided the design and organization of the study. MSC and FFQ wrote the manuscript. All authors discussed the results and worked on the discussion. 


\section{References}

1. Kase K, Wallis J, Kase T. Clinical therapeutic applications of the Kinesio Taping Method. 2 ed. Tokyo: Ken Ikai; 2003.

2. González-Iglesias J, Fernández-De-Las-Peñas C, Cleland JA, Huijbregts P, Gutiérrez-Vega MR. Short-term effects of cervical Kinesio Taping on pain and cervical range of motion in patients with acute whiplash injury: a randomized clinical trial. J Orthop Sports Phys Ther. 2009; 39(7): 515-21. LINK: http://www.jospt. org/doi/pdf/10.2519/jospt.2009.3072

3. Paoloni M, Bernetti A, Fratocchi G, Mangone M, Parrinelo L, Cooper MP, et al. Kinesio Taping applied to lumber muscles influences clinical and electromyographic characteristics in chronic low back pain patients. Eur J Phys Rehabil Med. 2011; 47(2): 237-44

4. Castro-Sánchez AM, Lara-Palomo IC, Matarán-Peñarrocha GA, Fernández-Sánchez M, Sánches-Labraca N, Arroyo-Morales M. KinesioTaping reduces disability and pain slightly in chronic nonspecific low back pain: a randomised trial. J Physiother. 2012; 58(2): 89-95. LINK: http://www.journalofphysiotherapy.com/ article/S1836-9553(12)70088-7/pdf

5. Nambi G, Shah BT. Kinesio Taping versus Mulligan's mobilization with movement in sub-acute lateral ankle sprain in secondary school Hockey players - comparative study. Int J Pharmac Health Care. 2012; 2(2): 136-49.

6. Chang HY, Wang $\mathrm{CH}$, Chou KY, Cheng SC. Could forearm Kinesio Taping improve strength, force sense and pain in baseball pitchers with medial epicondylitis? Clin J Sport Med. 2012; 22(4): 327-33.

7. Campolo M, Babu J, Dmochowska K, Scariah S, Varughese J. A comparison of two taping Techniques (Kinesio and Mcconnell) and their effect on anterior knee pain during functional activities. The Int J of Sports Physical Therapy. 2013; 8(2): 105-10. LINK: http://www.ncbi.nlm.nih.gov/pmc/articles/PMC3625789/pdf/ ijspt-08-105.pdf

8. Kachanathu SJ, Alenazi AM, Seif, HE, Hafez AR, Alroumim MA. Comparison between Kinesio Taping and a traditional physical therapy program in treatment of nonspecific low back pain. J Phys Ther Sci. 2014; 26(8): 1185-88. LINk: http://www.ncbi.nlm. nih.gov/pmc/articles/PMC4155216/pdf/jpts-26-1185.pdf

9. Lee YS, Bae SH, Hwang JA, Kim KY. The effects of Kinesio Taping on architecture, strength and pain of muscles in delayed onset muscle soreness of biceps brachii. J Phys Ther Sci. 2015; 27(2): 477-9. LINk: http://www.ncbi.nlm.nih.gov/pmc/articles/ PMC4339160/pdf/jpts-27-457.pdf
10. García-Muro F, Rodríguez-Fernández AL, Lucas AH. Treatment of myofascial pain in the shoulder with Kinesio Taping. A case report. Man Ther. 2010; 15(3): 292-5.

11. Kase K, Wallis J: The latest Kinesio Taping method. Tokyo: SkiJournal 2002.

12. Kuru T, Yaliman A, Dereli EE. Comparison of efficiency of Kinesio ${ }^{\circledR}$ taping and electrical stimulation in patients with patellofemoral pain syndrome. Acta Orthop Traumatol Turc. 2012; 46(5): 385-92. LINK: http://www.aott.org.tr/article/ view/5000011034/5000011186

13. Artioli DP, Bertolini GRF. Kinesio taping: aplicação e seus resultados na dor: revisão sistemática. Fisioter Pesq 2014; 21(1): 94-99. LINK: http://www.revistas.usp.br/fpusp/article/ view/80149/84042

14. Parreira PCS, Costa LCM, Takahashi $R$, Junior $L C H$, Junior $M A L$, Silva TM, Costa LOP. Kinesio Taping to generate skin convolutions is not better than sham taping for people with chronic nonspecific low back pain: a randomised trial. J Physiother. 2014; 60(2); 90-96. LINK: http://www.journalofphysiotherapy.com/ article/S1836-9553(14)00036-8/pdf

15. Thelen, M; Dauber, J; Stoneman, P. The clinical efficacy of Kinesio Tape for shoulder pain: a randomized, double-blinded, clinical trial. J Orthop Sports Phys Ther. 2008; 38(7); 389-395. LINK: http://www.jospt.org/doi/pdf/10.2519/jospt.2008.2791

16. Firth B, Dingley $P$, Davies ER, et al. The effect of Kinesio Tape on function, pain, and motoneuronal excitability in healthy people and people with achilles tendinopathy. Clin J Sport Med. 2010; 20(6): 416-421.

17. Briem, K. et al. Effects of Kinesio Tape compared with nonelastic sports tape and the untaped ankle during a sudden inversion perturbation in male athletes. J Orthop Sports Phys Ther. 2011; 41(5): 328-335. LINK: http://www.jospt.org/doi/pdf/10.2519/ jospt. 2011.3501

18. Francis RP, Marchant P, Johnson MI. Conventional versus acupuncture-like transcutaneous electrical nerve stimulation on cold-induced pain in healthy human participants: effects during stimulation. Clin Physiol Funct Imaging. 2011; 31(5): 363-70. LINK: http://onlinelibrary.wiley.com/doi/10.1111/j.1475097X.2011.01025.x/epdf

19. Parreira PCS, Costa LCM, Takahashi R, Junior LCH, Silva TM, Junior MAL, Pena Costa LOP. Do convolutions in Kinesio Taping matter? Comparison of two Kinesio Taping approaches in patients with chronic non-specific low back pain: protocol of a randomised Trial. J Physiother. 2013:59(1): 52.

20. Cheroto AC, Yamada EF. Efeito da TENS e da corrente interferencial na dor induzida pelo frio. Rev Bras Reabilitação e Atividade Física. 2014; 3(1): 7-13. LINk: file:///C:/Users/MARCELO/ Downloads/170-660-1-PB\%20(1).pdf 
21. Albahel F, Hafez AR, Zakaria AR, Al-ahaideb A, Buragadda $S$, Melam GR. Kinesio Taping for the treatment of mechanical low back pain. World Appl. Sci. J.2013; 22(1): 78-84.

22. Williams S, Whatman C, Hume PA, Sheerin K. Kinesio Taping in treatment and prevention of sports injuries. Sports Med. 2012; 42(2): 153-164

23. Aytar A, Ozunlu N, Surenkok O, Baltaci G, Oztop P, Karatas M. Initial effects of Kinesio $\AA$ taping in patients with patellofemoral pain syndrome: A randomized, double-blind study. Isokinetics and Exercise Science. 2011; 19:135-142. LINK: http://www. kinesiotaping.no/omoss/forskning/frontpage/aytar_2011.pdf

24. Lim ECW, Tay MGX. Kinesio Taping in musculoskeletal pain and disability that lasts for more than 4 weeks: is it time to peel off the tape and throw it out with the sweat? A systematic review with meta-analysis focused onpain and also methods of tape application. Br J Sports Med. 2015; 0:1-10. PubMed PMID: 25595290.

25. Karatas N, Bicici S, Baltaci G, Caner H. The Effect of Kinesio Tape application on functional performance in surgeons who have musculo-skeletal pain after performing surgery. Turk Neurosurg. 2012; 22(1): 83-9. LINK: http://www.turkishneurosurgery.org.tr/ pdf/pdf JTN 945.pdf

26. Batista CV, Ruaro JA, Ruaro MB, Dubiela A, Kerppers II, Suckow PPT, Knaut SAM, Fréz AR. Uso da Kinesio Taping na dor lombar: revisão sistemática. Cons Saúde. 2014; 13(1): 147-152. LINK: http://www.redalyc.org/articulo.oa?id=92930146019.

27. Parreira PCS, Costa LCM, Junior LCH, Lopes AD, Costa LOP. Current evidence does not support the use of Kinesio Taping in clinical practice: a systematic review. J Physiother. 2014; 60(1): 31-9. LINK: http://www.journalofphysiotherapy.com/article/ S1836- 9553(14)00009-5/pdf

\section{Comment on this article:}

\section{(f) $[$ in $8+\boldsymbol{S} P$}

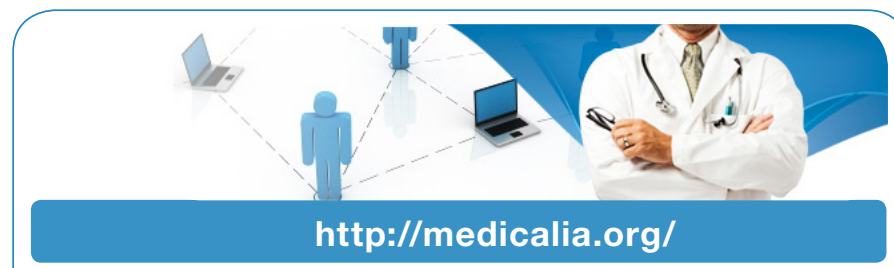

Where Doctors exchange clinical experiences, review their cases and share clinical knowledge. You can also access lots of medical publications for free. Join Now!

\section{Publish with iMedPub}

http://www.imed.pub

International Archives of Medicine is an open access journal publishing articles encompassing all aspects of medical science and clinical practice. IAM is considered a megajournal with independent sections on all areas of medicine. IAM is a really international journal with authors and board members from all around the world. The journal is widely indexed and classified Q1 in category Medicine. 